\title{
The effect of bluetongue virus serotype 8 on milk production and somatic cell count in Dutch dairy cows in 2008
}

\author{
I. M. G. A. Santman-Berends,${ }^{, 1}$ J. J. Hage,${ }^{*}$ T. J. G. M. Lam,${ }^{\star}$ † O. C. Sampimon, ${ }^{\star}$ and G. van Schaik \\ *GD Animal Health Service, PO Box 9, 7400AA Deventer, the Netherlands \\ †Dutch Udder Health Centre, PO Box, 7400 AA Deventer, the Netherlands
}

\begin{abstract}
The effect of bluetongue virus serotype 8 (BTV-8) infections was quantified on milk production and udder health. From July 2008 to December 2008, 1,074 seronegative cows in 15 herds that were not vaccinated against BTV-8 were tested every 3 wk for BTV-8 antibodies. Sampling stopped when cows seroconverted. Test-day records were provided and 3 traits were defined to evaluate the effect of BTV-8 on milk production and udder health: 1) the difference between observed and predicted fat- and protein-corrected milk production; 2) the natural logarithm of the somatic cell count (lnSCC); and 3) the occurrence of a new high SCC. In the default model, the variables were assumed influenced by BTV-8 when the test-day record of the seroconverted cow was taken within $30 \mathrm{~d}$ before seroconversion, thus, in the period in which the cow was infected. In sensitivity analyses, the time intervals were varied in which BTV-8 was assumed to affect milk production and udder health. During the study, 185 cows $(17 \%)$ had a subclinical infection and seroconverted and 77 had a test-day result within $30 \mathrm{~d}$ before seroconversion. In this period, in cows that seroconverted, the fat- and protein-corrected milk production was 52 (95\% confidence interval: 26 to 77 ) $\mathrm{kg}$ less than in the period before and after seroconversion and was 51 (95\% CI: 26 to 76$) \mathrm{kg}$ less than in cows that remained seronegative. When the time interval was increased to within $42 \mathrm{~d}$ before seroconversion, the milk production in BTV-8-seroconverted cows decreased by 61 (95\% CI: 28 to 94$) \mathrm{kg}$ compared with the period before and after seroconversion and decreased by 59 (95\% CI: 27 to 92) $\mathrm{kg}$ compared with cows that remained BTV-8 seronegative. No significant effect of BTV-8 was found on SCC and odds for a high SCC. Subclinical BTV-8 infection in dairy cattle results in a decreased milk production.
\end{abstract} Key words: bluetongue, cows, milk production, SCC

Received September 7, 2010.

Accepted December 7, 2010.

${ }^{1}$ Corresponding author: i.berends@gddeventer.com

\section{INTRODUCTION}

Historically, bluetongue did not occur in northwestern Europe, but in August 2006, bluetongue virus serotype 8 (BTV-8) emerged for the first time (van Wuijckhuise et al., 2006). In that year, clinical signs in cows seemed mild (Elbers et al., 2008) and dairy herds located in BTV-8-affected regions had a slight decrease in 305-d milk production compared with the period before BTV8 (van Schaik et al., 2008). In 2007, BTV-8 reemerged, spread over a larger area, and infected many herds (Santman-Berends et al., 2010a). Clinical signs in cows appeared more severe and besides a higher morbidity, farmers reported decreased milk production, increased numbers of mastitis cases, and increased SCC in BTV8-infected cows (Elbers et al., 2009).

An association between BTV-8 and udder health is expected because BTV-8 replicates in endothelial cells, causing cell injury to small blood vessels. This may lead to vascular thrombosis, tissue infarction, erythema and necrosis of the udder skin, and ulceration of the teats (Dercksen and Lewis, 2007; Williamson et al., 2008; Darpel et al., 2009). These lesions may lead to increased mastitis incidence and decreased milk production. Furthermore, BTV-8-infected cows can develop fever as a clinical sign, which can lead to increased SCC and decreased production. Although correct estimations of production losses are important to determine economic losses as a result of a BTV-8 infection, to our knowledge, no quantitative estimates about decreased milk production and mastitis as a result of BTV-8 infection on the cow level are available in the literature. This paper presents the effect of BTV-8 infections on milk production and SCC in dairy cows.

\section{MATERIALS AND METHODS}

\section{Study Population and Period}

The aim was to obtain data of 200 cows that seroconverted. Assuming that $20 \%$ of the seronegative cows would seroconvert in 2008, a sample size of 1,000 seronegative cows that were not vaccinated was required. In 2008, a voluntary vaccination program for BTV-8 was 
implemented in the Netherlands. In July 2008, 15 dairy herds in which the farmers decided not to vaccinate against BTV-8 were selected. All herds had HolsteinFriesians in a loose housing system with an average herd size of 109 cows older than $1 \mathrm{yr}$.

All dairy cows $>1$ yr $(\mathrm{n}=1,175)$ were tested for BTV antibodies in blood using a commercial competitive ELISA test (Pourquier, Montpellier, France) with a sensitivity of $100 \%$ and a specificity of $99.8 \%$ (based on an unpublished internal validation at the animal health service and Kramps et al., 2008).

The 1,074 cows that tested seronegative for BTV-8 entered the study, and were subsequently tested every 3 wk between July and December 2008. When cows seroconverted in this period, BTV-8 infection was assumed and further sampling was stopped. In the cows that remained seronegative, sampling ceased in December 2008 when the vector activity-free period began.

\section{Data Collection}

Milk production and SCC data from January 2006 to June 2009 of all cows in the 15 herds were provided by the Dutch Royal Cattle Syndicate (CRV). These data described 4 to 6 weekly test-day results of every cow in lactation and contained the following information:

- Herd level: unique herd identification (UHI)

- Cow level: identification (ID) number, date of the start of the lactation, and parity

- Test-day level: date, DIM, delivered $\mathrm{kg}$ of milk, delivered $\mathrm{kg}$ of fat, delivered $\mathrm{kg}$ of protein, SCC, predicted $\mathrm{kg}$ of milk, predicted $\mathrm{kg}$ of fat, and predicted $\mathrm{kg}$ of protein.

The complete data set contained 18,689 test-day results of 1,074 cows with 21.5 (minimum 1 ; maximum 42) test-day results per cow. The data provided by CRV was combined with the serology results, which contained results of 6,365 blood samples with 5 samples per cow (minimum 1; maximum 7).

\section{Milk Production and SCC}

For the analysis of the effect of BTV-8 on milk production and udder health, variables were analyzed; 1) the difference between observed and predicted fat- and protein-corrected milk production (FPCM; $\boldsymbol{\Delta} \boldsymbol{F} \boldsymbol{P C M}), 2$ ) the SCC, and 3) occurrence of a new high SCC (HSCC).

The predicted milk production is a standard variable in the Netherlands and is calculated by CRV for each cow for every test day. This trait is corrected for the observed 305-d milk production in the previous lactation (when parity $>1$ ), the observed production on the prior test day, the DIM, and parity (CRV, 2010a). For the analysis of milk production, the amount of milk delivered and predicted was corrected for FPCM according to the following formula:

$$
\begin{aligned}
& F P C M=[0.337+(0.116 \times \% \text { fat }) \\
& +(0.06 \times \% \text { protein })] \times k g \text { of milk } .
\end{aligned}
$$

Thereafter, $\triangle F P C M$ was calculated as the difference between the observed and predicted FPCM.

For the effect of BTV-8 on SCC, the natural log (lnSCC) was used. In addition, the probability of the occurrence of a new HSCC was analyzed in which a case of HSCC was defined as: 1) an increase in SCC from $<150,000$ cells $/ \mathrm{mL}$ to $>150,000$ cells $/ \mathrm{mL}$ in a heifer, and 2) an increase in SCC from $<250,000$ cells $/ \mathrm{mL}$ to $>250,000$ cells $/ \mathrm{mL}$ in a multiparous cow. This definition was based on the currently used threshold levels in the Netherlands (Sampimon et al., 2010).

\section{Statistical Analyses}

Descriptive analyses were performed on the data of the cows that remained seronegative and of those that seroconverted. All cows $>1$ yr were monitored for seroconversion. To study the effect of BTV-8 infections on milk production and SCC, only the data of lactating cows were included in the analyses.

The dependent variables $\triangle F P C M$ and $\operatorname{lnSCC}$ were both normally distributed and new HSCC had a binomial distribution (yes $=1$ or no $=0$ ). For the analyses of $\triangle F P C M$, and lnSCC, multi-level linear mixed models with a Gaussian distribution and an identity-link function were used. For the analysis of the effect of a BTV-8 infection on a new HSCC, a multi-level logistic regression with a logit-link function in Stata version 11 (Stata Corporation, College Station, TX) was used.

For the analysis, all cows present in the studied herds were assigned to 1 of 2 mutually exclusive categories based on their status for BTV-8. Cows that remained seronegative between July and December 2008 were assigned to susceptible (S) status and cows that seroconverted during the study period were assigned to infected (I) status.

The variable of interest was affected period $\left(A F P_{i j}\right)$, which gave an estimate of $\triangle F P C M, \operatorname{lnSCC}$, and new HSCC for seroconverted cows around the moment of BTV-8 infection. This variable was estimated for 3 classes of cows: 1) cows that were infected with BTV-8 during the study in the period that was assumed in- 
Affected period in default model

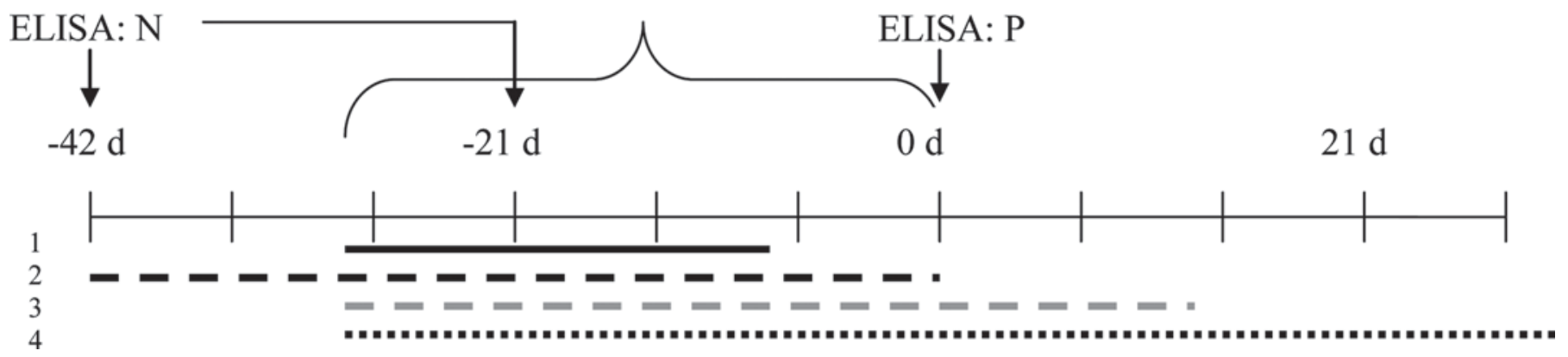

Figure 1. Bluetongue virus serotype 8 (BTV-8) testing scheme with the default period in which the milk production and SCC of the cows were assumed affected by BTV-8, and with 4 alternative affected periods. $\mathrm{N}=$ seronegative and $\mathrm{P}=$ positive for the detection of antibodies. ${ }^{1} \mathrm{BTV}$-8-affected period was 30 to $10 \mathrm{~d}$ before seroconversion; ${ }^{2} \mathrm{BTV}$-8-affected period was 42 to 0 d before seroconversion; ${ }^{3} \mathrm{BTV}-8$-affected period was $30 \mathrm{~d}$ before seroconversion until $15 \mathrm{~d}$ post seroconversion; ${ }^{4} \mathrm{BTV}$-8-affected period was $30 \mathrm{~d}$ before seroconversion until $30 \mathrm{~d}$ post seroconversion.

fluenced by BTV-8; 2) the same cows sampled either before or after the period in which they were assumed influenced by BTV-8; and 3) cows that remained seronegative during the entire study period. This division in categories was made to compare the seroconverted cows in the affected period to themselves before and after BTV-8 infection and to cows that remained seronegative.

In the model, corrections were made for possible confounding factors such as year, BTV-8 status, parity, DIM, and for clustering of observations within herds and cows.

Based on the literature (Guyot et al., 2008; Dal Pozzo et al., 2009), it was assumed that BTV-8 infection occurred between 35 and $15 \mathrm{~d}$ before the date that seroconversion was detected. Therefore, a test-day measure was assumed influenced by BTV-8 when it was taken within $30 \mathrm{~d}$ before the date on which seroconversion was measured (Figure 1).

The models that were used can be described as:

$$
\begin{aligned}
Y_{i j}=\mu_{i j}+ & \beta_{1} A F P_{i j}+\beta_{2} y r_{i j}+\beta_{3} \text { mnd }_{i j}+\beta_{4} \text { par }_{i j} \\
& +\beta_{5} \text { dlac }_{i j}+C_{i}+H_{j}+\varepsilon_{i j},
\end{aligned}
$$

where $Y_{i j}=$ dependent variable for each cow $(i)$ in each herd $(j): \triangle F P C M, \operatorname{lnSCC}$, or HSCC; $\mu_{i j}=$ intercept for each cow $(i)$ in each herd $(j) ; \beta_{1} A F P_{i j}=$ variable of interest for each cow $(i)$ in each herd $(j)$ : test-day of seroconverted [i.e., infected cows (I) that were affected by BTV-8 (1: seroconverted), test-day measures of seroconverted cows (I) before or post seroconversion (2: seroconverted pre or post), thus, between 2006 and June 2008 and after December 2008, and test-day measures that were not affected by BTV-8 because cows remained seronegative throughout the study (3: seronegative)]; $\beta_{2} y r_{i j}=2006,2007,2008$, or 2009; $\beta_{3} m n d_{i j}=$ mo 1, 2 , $3 \ldots 10,11,12$; and $\beta_{4}$ par $_{i j}=$ parity 1 (heifer), 2 , or $>2$ for each cow $(i)$ in each herd $(j)$ for the analyses of SCC and odds for a new HSCC. Parity was not included in the $\triangle F P C M$ model because the predicted FPCM was already corrected for parity. Term $\beta_{5} d l a c_{i j}=$ DIM $(0$ to 60,60 to 120 , or $>120$ ) for each cow $(i)$ in each herd $(j)$ for the analyses of SCC and odds for a new HSCC. Days in milk were not included in the $\triangle F P C M$ model because the predicted FPCM was already corrected for DIM. Term $C_{i}=$ random cow effect, $H_{j}=$ random herd effect, and $\varepsilon_{i j}=$ random error for each cow $(i)$ in each herd $(j)$.

The normality of the residuals of the model was monitored with normal plots and skewness and kurtosis tests.

\section{Sensitivity Analyses}

In the sensitivity analysis, the effect of different timeintervals in which $\triangle F P C M, \operatorname{lnSCC}$, and the odds for a new HSCC were affected by BTV-8 infection, were determined. The BTV-8 affected interval was varied to between 30 and $10 \mathrm{~d}$ before seroconversion and varied to between 42 and $0 \mathrm{~d}$ ( $6 \mathrm{wk}$ ) before seroconversion (Figure 1) for all 3 dependent variables to determine if the results were very sensitive to the time interval that was assumed affected by BTV-8.

It is possible that a cow that did not recover from the BTV-8 infection after seroconversion was not detected. Then, the $\triangle F P C M, \operatorname{lnSCC}$, and the odds for a new HSCC could still be affected by BTV-8 for a short period after seroconversion was detected. Thus, the BTV8-affected time interval was varied from $30 \mathrm{~d}$ before 
seroconversion to $15 \mathrm{~d}$ post seroconversion and from 30 $\mathrm{d}$ before seroconversion to $30 \mathrm{~d}$ post seroconversion in the sensitivity analyses (Figure 1).

\section{RESULTS}

\section{Descriptive Data}

During the study, 185 (17\%) of the 1,074 initially seronegative cows seroconverted. The highest percentage of these seroconversion occurred in September $(7.1 \%$; $\mathrm{n}$ $=72$ ). None of the185 seroconverted cows showed clinical signs of BTV-8 infection. In each of the 15 herds seroconversion occurred. On average, 24\% (95\% CI: 9 to $39 \%$ ) of the initially seronegative cows seroconverted in a herd.

From the 185 cows that seroconverted, 127 were lactating. For 77 of these cows, a test-day measurement was available within $30 \mathrm{~d}$ before the date that seroconversion was detected and could be included in the default analysis. Of the remaining 50 cows, 44 cows had the nearest test-day between 50 and $30 \mathrm{~d}$ before seroconversion, and of 6 cows, the nearest test-day measure was more than $50 \mathrm{~d}$ before seroconversion.

The difference between observed and predicted FPCM during the BTV-8 period in 2008 was -2.3 (95\% CI: -3.5 to -1.1$) \mathrm{kg} / \mathrm{d}$ for cows that seroconverted within $30 \mathrm{~d}$ before seroconversion, whereas it was 0 (95\% CI: -0.4 to 0.4$) \mathrm{kg}$ in 2007 , when no seroconversion occurred (Table 1). The SCC (111 cells/mL; 95\% CI: 85 to 144) and the percentage of cows that had a new HSCC $(13.0 \%$; 95\% CI: 5.3 to $20.7 \%$ ) was higher in the period in which the cows seroconverted compared with the same period in 2007 (100 cells $/ \mathrm{mL} ; 95 \%$ CI: 89 to 113 and $5.6 \%$; $95 \%$ CI: 3.0 to $8.2 \%$, respectively; Table 1).

\section{Effect of BTV-8 on Milk Production, SCC, and Occurrence of New HSCC}

The multi-level model estimated that milk production $(\triangle F P C M)$ was decreased in cows that seroconverted for BTV-8. A BTV-8-positive cow had a decreased $\triangle F P C M$ of 1.7 (95\% CI: 0.9 to $2.6, P<0.01) \mathrm{kg} / \mathrm{d}$ compared with the period that was not affected by BTV-8. In addition, compared with cows that remained seronegative, $\triangle F P C M$ around seroconversion was decreased by 1.7 (95\% CI: 0.9 to $2.5, P<0.01) \mathrm{kg} / \mathrm{d}$ over a $30-\mathrm{d}$ period. This meant that the milk production in a BTV8 -infected cow was decreased by a total of 51 (95\% CI: 26 to 76$)$ to 52 (95\% CI: 26 to 77$) \mathrm{kg}$ during the $30-\mathrm{d}$ period (Table 2).

Seroconverted cows had no increase in $\operatorname{lnSCC}$ compared with the period before seroconversion and compared with cows that remained seronegative (Table 2).

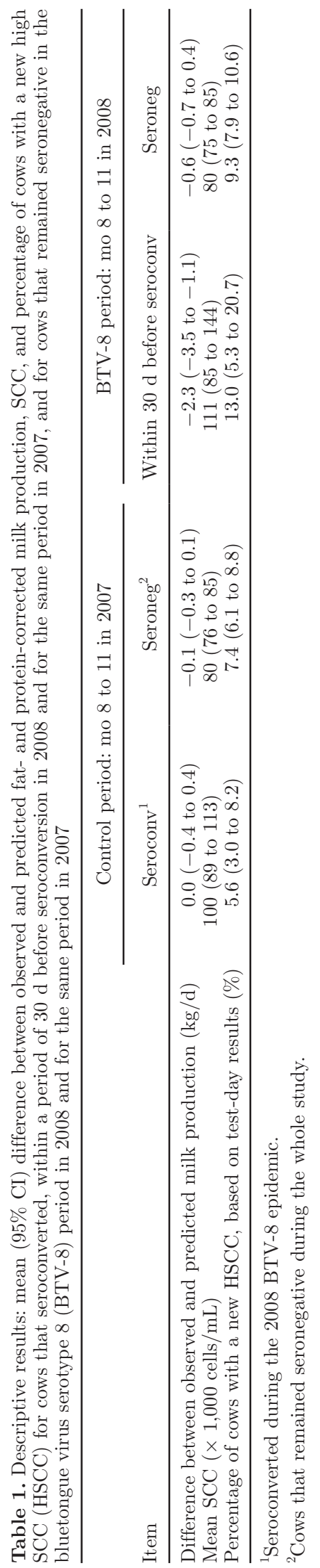


Table 2. Results of the multi-level models for the effect of bluetongue virus serotype 8 (BTV-8) infection within $30 \mathrm{~d}$ before seroconversion on milk production, SCC, and odds for a high SCC (HSCC) with the categories for BTV-8 status, estimates, $95 \%$ CI, and $P$-values (n $=77$ valid observations from seroconverted cows)

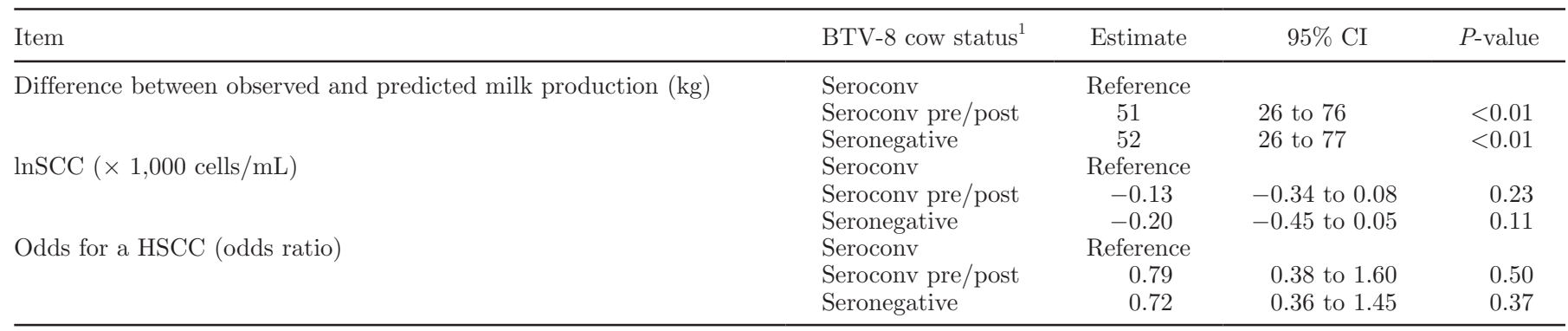

${ }^{1}$ Seroconv $=$ seroconverted for BTV-8 during the 2008 BTV-8 epidemic in the period that could be affected by BTV-8; Seroconv pre/post $=$ cows that seroconverted during the 2008 BTV-8 epidemic before (before July 2008) or post (after December 2008) the period that could be affected by BTV-8; Seronegative = cows that remained seronegative during the 2008 BTV-8 epidemic.

Cows that seroconverted for BTV-8 had an odds ratio of 1.3 (95\% CI: 0.6 to 2.6) for the occurrence of HSCC compared with the period before seroconversion and had an odds ratio of 1.4 (95\% CI: 0.7 to 2.8) for the occurrence of HSCC compared with that of cows that did not seroconvert. These odds ratios were not statistically significant (Table 2).

\section{Sensitivity Analyses}

When the default interval during which BTV-8 could affect milk production and SCC was changed to 30 to $10 \mathrm{~d}$ before seroconversion, the number of valid observations decreased to 56 . The effect on $\triangle F P C M$ per day remained approximately the same at a decrease of 1.7 (95\% CI: 0.7 to 2.7$) \mathrm{kg} / \mathrm{d}$. The BTV-8-affected period was decreased to $20 \mathrm{~d}$, which meant that the total milk production per BTV-8-affected cow decreased to 34 (95\% CI: 14 to $53 ; P<0.01$ ) $\mathrm{kg}$ compared with that in the period that was not affected by BTV-8, and decreased to 33 (95\% CI: 13 to $53 ; P<0.01) \mathrm{kg}$ compared with that of cows that remained seronegative. The effect of BTV-8 on $\operatorname{lnSCC}$ and the occurrence of new HSCC increased (Table 3). Between 30 and $10 \mathrm{~d}$ before seroconversion, seroconverted cows had a higher lnSCC compared with that of cows that remained seronegative (Table 3). Additionally, between 30 and $10 \mathrm{~d}$ before seroconversion, the odds for a new HSCC increased for seroconverted cows compared with the cows that remained seronegative and compared with themselves before and after the period that could be affected by BTV-8, but remained not significant in accordance with the default time interval (Table 3).

The $\operatorname{lnSCC}$ and the odds of a new HSCC in which the BTV-8-affected interval was not different for $42 \mathrm{~d}$ before seroconversion (91 valid observations; Table 3). In addition, the results of $\triangle F P C M$ per day decreased slightly to 1.5 (95\% CI: 0.7 to $2.2 ; P<0.01) \mathrm{kg} / \mathrm{d}$ com- pared with the period before or after the period that was affected by BTV-8, and to 1.4 (95\% CI: 0.6 to 2.2; $P<0.01) \mathrm{kg} / \mathrm{d}$ compared with cows that remained seronegative. Nevertheless, when $\triangle F P C M$ was calculated for the whole affected period of $42 \mathrm{~d}$, BTV-8-affected cattle had a decreased milk production of 61 (95\% CI: 28 to 94) $\mathrm{kg}$ compared with themselves before and after the period that was affected by BTV-8 and a decreased milk production of 59 (95\% CI: 27 to 92) kg compared with cows that remained seronegative.

When the BTV-8-affected time interval was prolonged to 15 or $30 \mathrm{~d}$ post seroconversion, the associations between BTV-8 infection and the $\triangle F P C M$ decreased (Table 3).

\section{DISCUSSION}

In our study, $17 \%$ of the initially seronegative cows seroconverted for BTV-8, indicating that they became infected. All cows experienced a subclinical infection. Besides a negative effect on fertility (Santman-Berends et al., 2010b), it appeared that a BTV-8 infection decreased milk production. The total amount of decreased milk associated with a BTV-8 infection in our study was estimated at approximately $51 \mathrm{~kg}$ per cow, which is about $0.6 \%$ of the yearly milk production per cow in the Netherlands $(8,218 \mathrm{~kg}$; CRV, 2010b), and relates to an economic loss of $€ 6.12$ (95\% CI: $€ 3.12$ to $€ 9.12$ ) per BTV-8 infected cow in a quotum situation (Huijps et al., 2008). A decrease in milk production associated with BTV-8 infections supports reports by van Schaik et al. (2008) and Elbers et al. (2009). van Schaik et al. (2008) found that the net return of 305-d milk production significantly decreased in dairy herds located in BTV-8-infected regions in the bluetongue period in 2006 compared with the period before the outbreak. Elbers et al. (2009) reported that, during the 2007 BTV-8 epidemic, $24 \%$ of the infected cows had a decrease in 
Table 3. Results of the sensitivity of the multi-level models for the effect of bluetongue virus serotype 8 (BTV-8) infection in different time intervals around seroconversion on milk production, log-transformed SCC (lnSCC), and the odds (OR) for a new high SCC (HSCC) with the categories for BTV-8 status, estimates, 95\% CI, and $P$-values

\begin{tabular}{|c|c|c|c|c|c|}
\hline Item & BTV-8-affected period & BTV -8 cow status ${ }^{1}$ & Estimate & $95 \% \mathrm{CI}$ & $P$-value \\
\hline \multirow{9}{*}{$\begin{array}{l}\text { Difference between observed and } \\
\text { predicted milk production }(\mathrm{kg})\end{array}$} & \multirow[t]{3}{*}{30 to $10 \mathrm{~d}$ before seroconversion $(\mathrm{n}=56)$} & Seroconv & Reference & & \\
\hline & & Seroconv pre/post & 34 & 14 to 53 & $<0.01$ \\
\hline & & Seronegative & 33 & 13 to 53 & $<0.01$ \\
\hline & \multirow[t]{3}{*}{42 to $0 \mathrm{~d}$ before seroconversion $(\mathrm{n}=91)$} & Seroconv & Reference & & \\
\hline & & Seroconv pre/post & 61 & 28 to 94 & $<0.01$ \\
\hline & & Seronegative & 59 & 27 to 92 & $<0.01$ \\
\hline & \multirow[t]{3}{*}{$30 \mathrm{~d}$ before, $15 \mathrm{~d}$ post seroconversion $(\mathrm{n}=138)$} & Seroconv & Reference & & \\
\hline & & Seroconv pre/post & 27 & -0.4 to 54 & 0.05 \\
\hline & & Seronegative & 26 & -1.2 to 52 & 0.06 \\
\hline \multirow[t]{9}{*}{$\operatorname{lnSCC}(\times 1,000$ cells $/ \mathrm{mL})$} & \multirow[t]{3}{*}{30 to $10 \mathrm{~d}$ before seroconversion $(\mathrm{n}=56)$} & Seroconv & Reference & & \\
\hline & & Seroconv pre/post & -0.21 & -0.46 to 0.03 & 0.09 \\
\hline & & Seronegative & -0.29 & -0.57 to -0.01 & 0.04 \\
\hline & \multirow[t]{3}{*}{42 to $0 \mathrm{~d}$ before seroconversion $(\mathrm{n}=91)$} & Seroconv & Reference & & \\
\hline & & Seroconv pre/post & -0.15 & -0.35 to 0.04 & 0.13 \\
\hline & & Seronegative & -0.23 & -0.47 to 0.01 & 0.06 \\
\hline & \multirow[t]{3}{*}{$30 \mathrm{~d}$ before, $15 \mathrm{~d}$ post seroconversion $(\mathrm{n}=138)$} & Seroconv & Reference & & \\
\hline & & Seroconv pre/post & -0.09 & -0.25 to 0.07 & 0.25 \\
\hline & & Seronegative & -0.17 & -0.38 to 0.04 & 0.11 \\
\hline \multirow[t]{9}{*}{ Odds for new HSCC (odds ratio) } & \multirow[t]{3}{*}{30 to $10 \mathrm{~d}$ before seroconversion $(\mathrm{n}=56)$} & Seroconv & Reference & & \\
\hline & & Seroconv pre/post & 0.55 & 0.26 to 1.14 & 0.11 \\
\hline & & Seronegative & 0.51 & 0.24 to 1.04 & 0.07 \\
\hline & \multirow{3}{*}{42 to $0 \mathrm{~d}$ before seroconversion $(\mathrm{n}=91)$} & Seroconv & Reference & & \\
\hline & & Seroconv pre/post & 0.71 & 0.38 to 1.35 & 0.30 \\
\hline & & Seronegative & 0.66 & 0.35 to 1.23 & 0.19 \\
\hline & \multirow{3}{*}{$30 \mathrm{~d}$ before, $15 \mathrm{~d}$ post seroconversion $(\mathrm{n}=138)$} & Seroconv & Reference & & \\
\hline & & Seroconv pre/post & 0.91 & 0.53 to 1.60 & 0.76 \\
\hline & & Seronegative & 0.84 & 0.48 to 1.45 & 0.51 \\
\hline
\end{tabular}

${ }^{1}$ Seroconv $=$ seroconverted for BTV-8 during the 2008 BTV-8 epidemic in the period that could be affected by BTV-8; Seroconv pre/post $=$ cows that seroconverted during the 2008 BTV-8 epidemic before (before July 2008) or post (after December 2008) the period that could be affected by BTV-8; Seronegative $=$ cows that remained seronegative during the 2008 BTV-8 epidemic. 
milk production. The exact amount of decreased milk production per infected cow was not described in these earlier studies. Possibly, the decreased milk production associated with BTV-8 infections was caused by the immunosuppressive effects of the virus. A similar result was found for dairy herds that suffered from a subclinical infection of Bovine herpesvirus 1 (BHV1; Hage et al., 1998; van Schaik et al., 1999).

Quantification of the exact amount of decreased milk production caused by BTV-8 infection is important for the calculation of the economic consequences of a BTV-8 outbreak. Velthuis et al. (2010) calculated the economic losses due to BTV-8 in the Netherlands and used assumptions for the effect of BTV-8 on milk production. In their study, BTV-8 was assumed to decrease milk production by $5.4 \mathrm{~kg} / \mathrm{d}$ for a period of $10.5 \mathrm{~d}$. This resulted in a total decrease in milk production of $56 \mathrm{~kg}$ per BTV-8-infected cow. The amount of decreased daily milk production was higher compared with ours and the number of affected days was lower. Nevertheless, the total decrease of produced milk in their study was comparable to the decrease we found. In our study, all cows were subclinically infected with BTV-8, whereas in the study of Velthuis et al. (2010) this amount of decreased milk was extrapolated to clinically affected cows, which may have a larger decrease in milk production.

When cows show clinical signs of BTV-8, the effect on milk production might be higher. Kedmi et al. (2010) studied the effect of an epizootic hemorrhagic disease (EHDV) outbreak in Israel, a virus closely related to BTV, on milk production in cattle. They found a total decrease in milk production of $207 \mathrm{~kg}$ per cow in clinically affected herds, possibly caused by the interaction of high temperatures in Israel and clinical EHDV in cattle. On the other hand, the effect of BTV8 infections on milk production in our study possibly underestimates the decrease in milk production in clinically affected herds because all cattle were subclinically infected.

The effect of BTV-8 infection on SCC was less clear. No statistical significance in the default model was found. To our knowledge no papers have been published on the relationship between SCC, HSCC, and BTV-8 infection. Elbers et al. (2009) did describe that in 2007, BTV-8-infected herds had more cows with red teats or lesions on teats, or both.

The test used in our study was not serotype specific and theoretically serotypes other than BTV-8 could have been present. During the study period, BTV serotype 6 was found in the eastern part of the Netherlands. Measures for prevention of spread of the virus were taken and herds surrounding the affected herds were sampled. It appeared that BTV-6 did not spread extensively and only 13 cows in 13 herds became infected (ProMED, 2008; ProMED, 2009). The herds in our study were mainly located in the north of the Netherlands, far from the area in which BTV-6 emerged. Furthermore, in the monitoring and surveillance system in the Netherlands, which detected serotype 6, no other cases of BTV-6 than the 13 mentioned above, or other serotypes were found. Therefore, we believe that our results are only associated with BTV-8 and that other serotypes did not influence our results.

In the default model, the BTV-8-affected time interval was assumed 30 to $0 \mathrm{~d}$ before seroconversion. Based on the literature, it is known that BTV-8-neutralizing antibodies arise on average $14 \mathrm{~d}$ after infection (Dal Pozzo et al., 2009). In addition, in the prior seronegative sample $21 \mathrm{~d}$ before seroconversion was detected, the cows had a negative result for antibodies against BTV-8. Thus, seroconversion occurred $10 \mathrm{~d}$ before the date on which seroconversion was detected. Based on these numbers we assumed that BTV-8 infection occurred between 35 and 15 d before the date on which seroconversion was detected. Because sampling began $>35 \mathrm{~d}$ before seroconversion, cows were assumed not yet infected by BTV-8 and clinical signs of BTV-8 were seen 7 to $11 \mathrm{~d}$ after BTV-8 infection (Guyot et al., 2008; Dal Pozzo et al., 2009), we determined that the test-day measure was influenced by BTV-8 when it was taken in this defined time interval of 30 to $0 \mathrm{~d}$ before seroconversion.

Because uncertainty existed about the exact time interval in which BTV-8 infection would affect milk production and SCC, a sensitivity analysis was carried out with alternatives for the affected time-interval. The results of the 2 alternative intervals in which the BTV-8-affected time interval was changed to 30 to $10 \mathrm{~d}$ before seroconversion and to $42 \mathrm{~d}$ before seroconversion showed consistent results with the default model. All 3 intervals showed that BTV-8 had a significant negative effect on milk production. The estimates for the analyzed variables were not very sensitive for changing the BTV-8-affected time interval before seroconversion. Therefore, based on biological reasons and the results of the sensitivity analyses, the time interval from 30 to $0 \mathrm{~d}$ before seroconversion seemed the true period in which cattle suffer from a BTV-8 infection. When the BTV-8-affected time interval was prolonged to 15 or 30 d after seroconversion, effects of BTV-8 on production became smaller. This indicates that after seroconversion the milk production returned to normal levels.

\section{CONCLUSIONS}

Infection with BTV-8 had a negative influence on milk production of a cow. Cows that suffered from a sub- 
clinical BTV-8 infection had a decrease in milk production of about $1.7 \mathrm{~kg} / \mathrm{d}$ for a period of $30 \mathrm{~d}$. This meant that the total milk production of a BTV-8-infected cow decreased about $52 \mathrm{~kg}$. When the time interval in which it was assumed that cows were affected by BTV-8 was increased to within $42 \mathrm{~d}$ before seroconversion, the milk production in BTV-8-seroconverted cows decreased by $61 \mathrm{~kg}$ compared with that in the period before and after seroconversion, and decreased by $59 \mathrm{~kg}$ compared with that of cows that remained seronegative. Subclinical BTV-8 infection was associated with nonsignificant changes in lnSCC and in occurrence of new HSCC cows. Nevertheless, all cows were subclinically infected with BTV-8 and a larger effect of BTV-8 on milk production and SCC might have been observed in cows suffering from clinical BTV-8 infections.

\section{ACKNOWLEDGMENTS}

This study was financially supported by the Product Board for Livestock and Meat (PVV). Furthermore, we are grateful to the Dutch Royal Cattle Syndicate (CRV, Arnhem, the Netherlands) for providing the test-day data and the Dutch dairy farmers and veterinarians who cooperated in our study.

\section{REFERENCES}

CRV (Dutch Royal Cattle Syndicate). 2010a. Key parameters: E1 predicted yield. Accessed Jan. 25, 2010. https://www.cr-delta.nl/nl/ index-overcrdelta.htm.

CRV (Dutch Royal Cattle Syndicate). 2010b. CRV year statistics of 2009. Accessed Oct. 17, 2010. https://www.cr-delta.nl/servlets/ dbupload?id $=22742$.

Dal Pozzo, F., K. De Clercq, H. Guyot, E. Vendemeulebroucke, P. Sarradin, F. Vandenbussche, E. Thiry, and C. Saegerman. 2009. Experimental reproduction of bluetongue virus serotype 8 clinical diseases in calves. Vet. Microbiol. 136:352-358.

Darpel, K. E., P. Monaghan, S. J. Anthony, H. Takamatsu, and P. P. Mertens. 2009. Bluetongue virus in the mammalian host and the induced immune response. Pages 265-284 in Bluetongue. P. Mellor, M. Baylis, and P. Mertens, ed. Elsevier, London, UK.

Dercksen, D., and C. Lewis. 2007. Bluetongue virus serotype 8 in sheep and cows: A clinical update. In Pract. 29:314-318.

Elbers, A. R. W., A. Backx, E. Meroc, G. Gerbier, C. Staubach, G. Hendrickx, A. N. van der Spek, and K. Mintiens. 2008. Field observations during the bluetongue serotype 8 epidemic in 2006. I. Detection of first outbreaks and clinical signs in sheep and cows in Belgium, France and the Netherlands. Prev. Vet. Med. 87:2130.

Elbers, A. R. W., A. N. van der Spek, and P. A. van Rijn. 2009. Epidemiologic characteristics of bluetongue virus serotype 8 laboratory- confirmed outbreaks in the Netherlands in 2007 and a comparison with the situation in 2006. Prev. Vet. Med. 92:1-8.

Guyot, H., A. Mauroy, N. Kirschvink, F. Rollin, and C. Saegerman. 2008. Clinical aspects of bluetongue in ruminants. Pages $34-52$ in Bluetongue in Northern Europe. C. Saegerman, F. ReviriegoGordeja, and P.-P. Pastoret, ed. OIE Publications, Paris, France.

Hage, J. J., Y. H. Schukken, T. Dijkstra, H. W. Barkema, P. H. R. van Valkengoed, and G. H. Wentink. 1998. Milk production and reproduction during a subclinical bovine herpesvirus 1 infection on a dairy farm. Prev. Vet. Med. 34:97-106.

Huijps, K., T. J. G. M. Lam, and H. Hogeveen. 2008. Costs of mastitis: Facts and perception. J. Dairy Res. 75:113-120.

Kedmi, M., M. Van Straten, E. Ezra, N. Galon, and E. Klement. 2010. Assessment of the productivity effects associated with epizootic hemorrhagic disease in dairy cattle. J. Dairy Sci. 93:2486-2495.

Kramps, J. A., K. van Maanen, M. H. Mars, J. K. Popma, and P. van Rijn. 2008. Validation of a commercial ELISA for the detection of bluetongue virus (BTV)-specific antibodies in individual milk samples of Dutch dairy cows. Vet. Microbiol. 130:80-87.

ProMED. 2008. PRO/AH/EDR > Bluetongue - Europe (76): UK ex France BTV-1, Netherlands BTV-6. Accessed Oct. 16, 2010. http://www.promedmail.org/pls/apex/f?p=2400:1202:9317081018 1745:NO:F2400_P1202_CHECK_DISPLAY,F2400_P1202_PUB_ MAIL_ID:X,74919.

ProMED. 2009. PRO/AH/EDR> Bluetongue - Europe (07): BTV-6, BTV-11 update. Accessed Oct. 16, 2010. http://www.promedmail. org/pls/apex/f?p=2400:1202:93170810181745:NO:F2400_P1202 CHECK_DISPLAY,F2400_P1202_PUB_MAIL_ID:X,76418.

Sampimon, O., B. H. van den Borne, I. Santman-Berends, H. W Barkema, and T. J. G. M. Lam. 2010. Effect of coagulase-negative staphylococci on somatic cell count in Dutch dairy herds. J. Dairy Res. 77:318-324.

Santman-Berends, I. M. G. A., C. J. M. Bartels, G. van Schaik, J. A. Stegeman, and P. Vellema. 2010a. The increase in seroprevalence of bluetongue virus (BTV) serotype 8 infections and associated risk factors in Dutch dairy herds, in 2007. Vet. Microbiol. $142: 268-275$.

Santman-Berends, I. M. G. A., J. J. Hage, P. A. van Rijn, J. A. Stegeman, and G. van Schaik. 2010b. BTV-8 in Dutch cows in 2008, fertility performance and the infection status of the offspring. Theriogenology 74:1377-1384.

van Schaik, G., I. M. G. A. Berends, H. van Langen, A. R. W. Elbers, and P. Vellema. 2008. Seroprevalence of bluetongue serotype 8 in cows in the Netherlands in spring 2007, and its consequences. Vet. Rec. 163:441-444.

van Schaik, G., M. Shoukri, S. E. Martin, Y. H. Schukken, M. Nielen, J. J. Hage, and A. A. Dijkhuisen. 1999. Modeling the effect of an outbreak of bovine herpesvirus type 1 on herd-level milk production of Dutch dairy farms. J. Dairy Sci. 82:944-952.

van Wuijckhuise, L., D. Dercksen, J. Muskens, J. de Bruijn, M. Scheepers, and R. Vrouenraets. 2006. Bluetongue in the Netherlands; Description of the first clinical cases and differential diagnosis. Common symptoms just a little different and in too many herds. Tijdschr. Diergeneeskd. 131:649-654.

Velthuis, A. G. J., H. W. Saatkamp, M. C. M. Mourits, A. A. de Koeijer, and A. R. W. Elbers. 2010. Financial consequences of the Dutch bluetongue serotype 8 epidemics of 2006 and 2007. Prev. Vet. Med. 93:294-304.

Williamson, S., N. Woodger, and K. Darpel. 2008. Differential diagnosis of bluetongue in cows and sheep. In Pract. 30:242-251. 